\title{
Meta-Analysis of Zinc Deficiency and Its Influence Factors in Children Under 14-year-old in China
}

Cai-J in $Y^{1}$, J ing-Ying $S^{1}$ and Gang-Xi $L^{1,2,3 *}$ ${ }^{1}$ Department of Pediatrics, The First Affiliated Hospital of Xiamen University, The School of Clinical Medicine, Fujian Medical University, Xiamen, China

${ }^{2}$ Pediatric Key Laboratory of Xiamen, Xiamen, China ${ }^{3}$ Institute of Pediatrics, School of Medicine, Xiamen University, Xiamen, China

*Corresponding author: Lin Gang-Xi, Department of Pediatrics, The First Affiliated Hospital of Xiamen University, The School of Clinical Medicine, Fujian Medical University, Xiamen, China; Pediatric Key Laboratory of Xiamen, Xiamen, China; Institute of Pediatrics, School of Medicine, Xiamen University, Xiamen 361003 , China

Received: April 13, 2021; Accepted: June 07, 2021; Published: June 14, 2021

\begin{abstract}
Background: In recent years, zinc deficiency in children has attracted global attention. There are some differences in zinc deficiency in different countries and regions. However, there are few multi-center and large-sample studies on zinc deficiency in children in mainland China.
\end{abstract}

Objective: To evaluate the status of zinc deficiency and its influence factors in children under 14-year-old in mainland China, and to provide evidence-based evidence for the strategy of prevention and treatment of zinc deficiency in children.

Methods: PubMed, Embase, CNKI and other databases were searched about the cross-sectional survey literature on zinc deficiency and its influencing factors of under 14-year-old children in mainland China from 2005 to 2021. Stata 14.0 statistical software was used for Meta-analysis. Two independent reviewers identified eligible studies.

Results: We identified 55 studies with 292,877 healthy children and adolescents in the Meta-analysis. The overall zinc deficiency rate was $27.0 \%$ (95\% Cl 22.8\%-31.3\%). From coastal areas of China showed that the zinc deficiency rate was $21.7 \%(95 \% \mathrm{Cl} 16.2 \%-27.1 \%)$ as $29.6 \%(95 \% \mathrm{Cl} 24.9 \%$ $34.4 \%)$ from inland area of China. The zinc deficiency rate in the male group was greater than in the female group, and the difference was statistically significant $[\mathrm{OR}=1.052,95 \% \mathrm{Cl}(1.019,1.087), \mathrm{p}=0.002]$. The zinc deficiency rate in infant group was higher than that in toddler group [OR $=1.38,95 \% \mathrm{Cl}(1.16$, 1.64), $p=0.000$ ], preschool group [OR=1.475, $95 \% \mathrm{Cl}(1.163,1.870), p=0.001]$, and school-age group [OR=1.746, $95 \% \mathrm{Cl}(1.257,2.425), p=0.001]$, with statistical significance. There was no significant difference in zinc deficiency rate between the toddler group and the preschool group [OR=1.059, 95\% $\mathrm{Cl}(0.918$, $1.222), p=0.429]$, the toddler group and the school-age group [OR=1.136, $95 \% \mathrm{Cl}(0.848,1.523), p=0.394]$, and the preschool group and the school-age group [OR $=0.986,95 \% \mathrm{Cl}(0.754,1.291), p=0.919]$. There was no statistically significant difference in zinc deficiency rate between the groups of well-educated and the poor-educated dietary provider. $(\mathrm{OR}=1.095,95 \% \mathrm{Cl}(0.867,1.383)$, $\mathrm{p}=0.446$ ), and no statistical significance in zinc deficiency rate between urban group and rural group [OR=1.152, 95\% $\mathrm{Cl}(0.810,1.637), \mathrm{p}=0.432]$.

Conclusions: At present, zinc deficiency in children and adolescents in mainland China is still serious, especially in infants. The zinc deficiency rate in male children was more serious than that of female children. The zinc deficiency rate of children in inland areas was higher than that in coastal areas. Factors such as different educational level of food providers and different areas from urban or rural were not the major influencing factors of zinc deficiency.

Keywords: Zinc; Zinc deficiency; Factors; Children; Meta-Analysis

\section{Background}

Zinc is an essential micronutrient distributed throughout the body, which is involved in a variety of metabolic processes in the body. Zinc deficiency will affect a variety of body functions, including growth and development, immune function, reproductive function and neurobehavioral development, which will bring serious harm to the health of the body. In 1963, Prasad et al. [1] reported on cases of adolescent hypogonadism and dwarfism caused by zinc deficiency [2]. Thus, uncovering the important impact of zinc deficiency on human health for the first time. In 1974, Moynahan [3] described that Acrodermatitis Enteropathica (AE) is associated with severe zinc deficiency, which is an autosomal recessive genetic disease related to zinc metabolism defects, further confirming zinc Importance to human health. It is reported that approximately 116,000 child death in 2011 was related to zinc deficiency, mainly due to the prevalence and severity of infectious diseases such as diarrhea [4]. Walker et al. [5] showed that the prevalence of zinc deficiency is more serious in three regions of the world (Africa, Asia and Latin America). There are different in the status of zinc deficiency in different countries. At 
present, there are few multi-center studies on zinc deficiency in China. The main purpose of this study is to conduct systematic reviews and meta-analysis by collecting relevant studies to explore the overall zinc deficiency status of children aged 0-14 years in mainland China in the past 15 years and some related influencing factors, in order to provide evidence-based basis and data support for the comprehensive prevention and treatment of zinc deficiency in children in China. The research results are reported as following.

\section{Methods}

\section{Literature and search strategy}

Search Chinese and English databases such as PubMed, Embase, Cochrane Library, Web of Science, China Biomedical Literature Database (CBM) and other Chinese and English databases until February 8, 2021. Search terms are "Zinc", "Zinc deficiency", "Zinc status", "Micronutrient deficiencies", "Micronutrient status", "Micronutrient deficiency", "China/Chinese", and "Child/Children". The search is based on a combination of subject terms and free words. And incorporate unpublished documents including dissertations, conference reports and other unpublished documents through manual retrieval and literature retrospective methods. The search is carried out independently by two reviewers, and when there is a disagreement, through consultation or a third reviewer joins in the analysis and discussion and reaches a consensus.

\section{Inclusion and exclusion criteria}

Inclusion criteria: 1) The subjects of the study were healthy children and adolescents aged 0-14 years in mainland China; 2) The outcome of the study is the plasma (serum) zinc level, and the testing equipment is not limited; 3) The types of studies include published and unrestricted A publicly published cross-sectional study on zinc levels and zinc deficiency in children; 4) The study languages are limited to Chinese and English.

Exclusion criteria: 1) The subject is in the period of acute infection and inflammation, such as fever, acute diarrhea and other diseases; 2) The outcome indicator of the study is not plasma (or serum) zinc, such as hair zinc, nail zinc and other detection methods; 3) The research sample size is less than 1000 cases, and the research time is earlier than 2005; 4) The literature for which the research data cannot be extracted; 5) The literature of systematic reviews or reviews, case reports, etc.

\section{Data extraction and quality evaluation}

Data extraction was conducted after literature screening, including the first author, publication year, research area, research sample size, zinc level and zinc deficiency rate, and related influencing factors. According to the cross-sectional study quality evaluation checklist recommended by the Agency for Healthcare Research Quality (AHRQ) [6], two researchers independently evaluated the quality of the final included studies. When there is a disagreement, discuss with the third researcher and reach an agreement. The evaluation list includes 11 items. For each item, the answer is "yes", "no" or "do not know". The total score is 11 points, of which the answer to "yes" is 1 point, and the answer to "no" or "do not know" The score is 0 . The higher the total score, the better the quality of the research. 0 to 3 are classified as low-quality studies, 4 to 7 are classified as mediumquality studies, and 8 to 11 are classified as high-quality studies.

\section{Statistical analysis}

Stata14.0 software (version 11) was used for statistical analysis. Q test and I 2 value were used to quantitatively evaluate the heterogeneity among the included studies. If there is no significant heterogeneity among the included studies or the heterogeneity is small ( $\mathrm{P} \geq 0.10$ and/ or I2 value $\leq 50 \%$ ), the fixed effects model is used for Meta-analysis; if the heterogeneity is large [ $\mathrm{P}<0.10$ and (or) I2 value $>50 \%]$, then use subgroup analysis, Meta regression or one-by-one elimination of sensitivity analysis to further analyze the source of heterogeneity. If there is still heterogeneity after treatment, then use random effects model for Meta-analysis, the analysis result is $\mathrm{P}<0.05$ indicating that the difference is statistically significant. The outcome indicators of zinc deficiency rate were expressed by odds ratio (OR value) and its 95\% confidence intervals (CI); the funnel chart method was used and the Egger test was used to quantitatively identify publication bias.

\section{Results}

\section{Literature search results}

Preliminary search was used to obtain 5835 documents, Endnote document management software was used to eliminate duplicate documents, and 278 documents were obtained by browsing document titles and abstracts to enter the full-text reading screening, and finally 55 documents [7-61] were included in the Meta-analysis and evaluation of this article. The sample size was 292,877 cases. The literature screening process is shown in Figure 1, and the basic information of the included literature is shown in Table 1.

\section{Literature quality evaluation results}

Literature quality evaluation results showed that the 55 included literatures were scored 3-9 points according to the AHRQ crosssectional study evaluation scale. Among them, 3 literatures scored more than 7 points, which were high-quality literature, and 37 literatures scored 4-7 points. They are medium-quality documents, 15 documents are scored 3 points, and they are low-quality documents.

\section{Meta-analysis results}

In this study, the overall zinc deficiency rate of children aged 0-14, the rate of zinc deficiency in different genders, different age groups, and the influencing factors of zinc deficiency were analyzed by Meta-

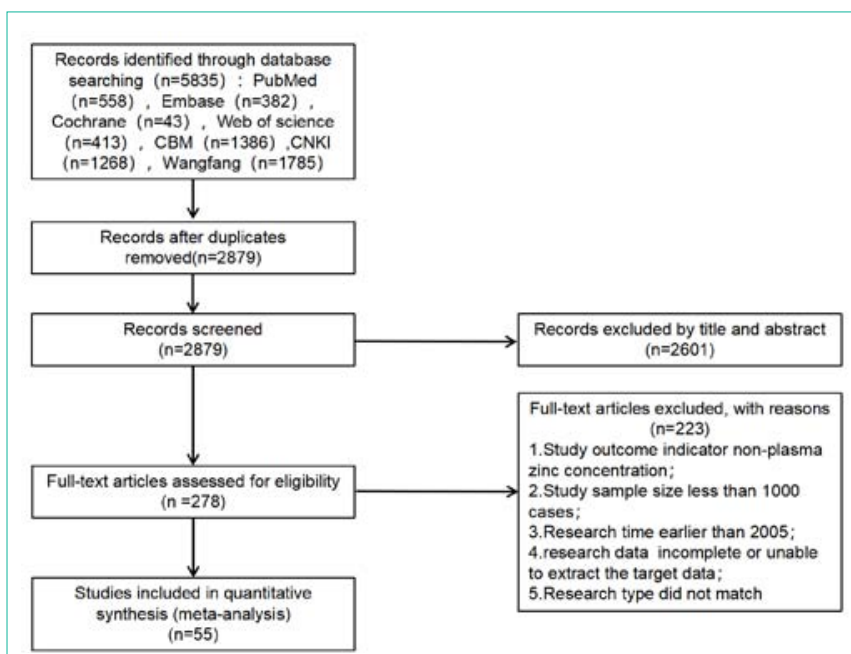

Figure 1: Flow chart of literature screening. 
Table 1: Characteristics of studies included in the meta-analysis.

\begin{tabular}{|c|c|c|c|}
\hline & Number of Studies & Sample Size & Research Serial Number \\
\hline Information of the Research & 55 & 292877 & $(7 \sim 61)$ \\
\hline Publication time (2006 2020) & - & - & - \\
\hline Research age group $(0 \sim 14 \mathrm{Y})$ & - & - & - \\
\hline Research areas ( 43 cities and towns in mainland China) & - & - & - \\
\hline Research Gender Group & 21 & 83952 & $(7,9 \sim 11,14 \sim 15,17 \sim 18,20,27 \sim 29,38 \sim 40,42 \sim 43,51 \sim 52,60 \sim 61)$ \\
\hline Male & - & 47162 & - \\
\hline Female & - & 36790 & - \\
\hline Education level of food providers group & 4 & 7406 & $(7,42,53,61)$ \\
\hline Well-educated & - & 4112 & - \\
\hline Poor-educated & - & 3294 & - \\
\hline Research area group & 5 & 10497 & $(7,32,36,42,50)$ \\
\hline Urban & - & 6875 & - \\
\hline Rural & - & 3622 & - \\
\hline
\end{tabular}

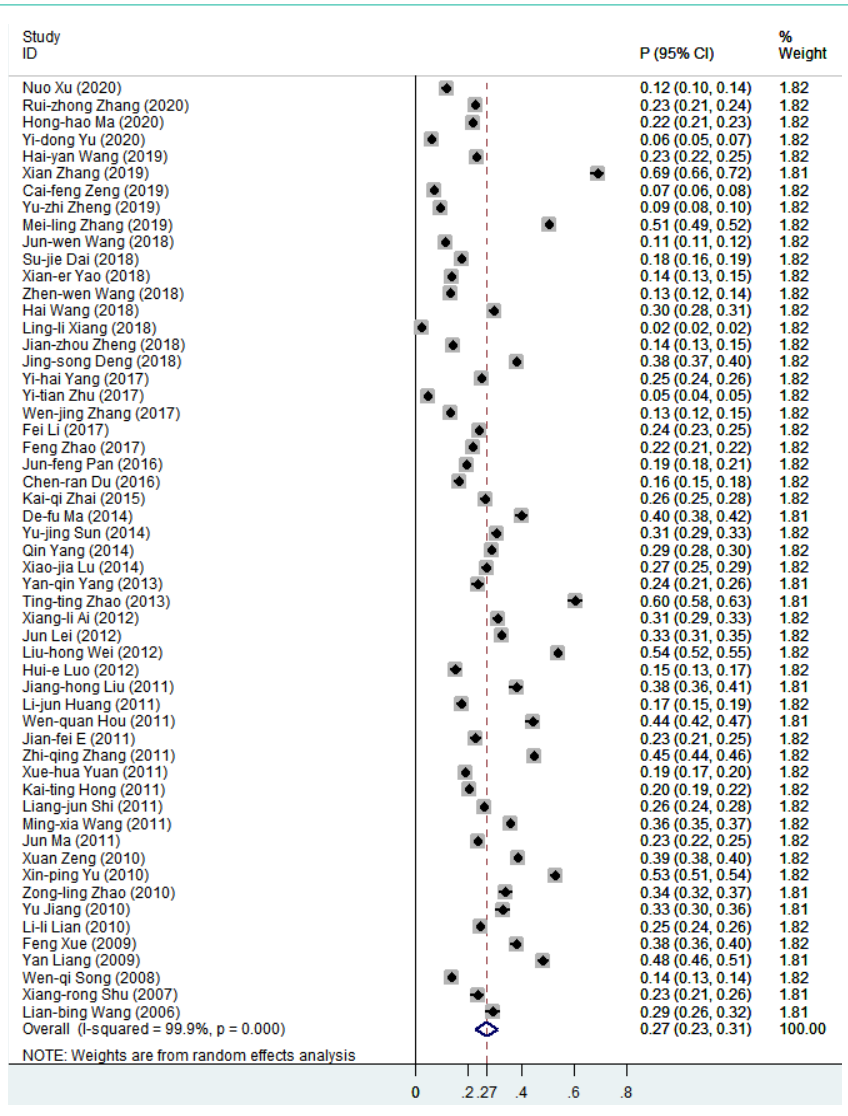

Figure 2: Meta-analysis of zinc deficiency rate in Chinese children forest plot.

analysis. The results are as following.

The results of the analysis of the overall zinc deficiency rate in children: A heterogeneity test was carried out on 55 included literatures, and the results showed that $\mathrm{I}^{2}=99.9 \%, \mathrm{p}=0.000$, there is obvious heterogeneity. The sensitivity analysis method was eliminated one by one, and it was found that the heterogeneity did not change significantly, so the random effects model was used for the meta-analysis. Meta-analysis results show that the zinc deficiency

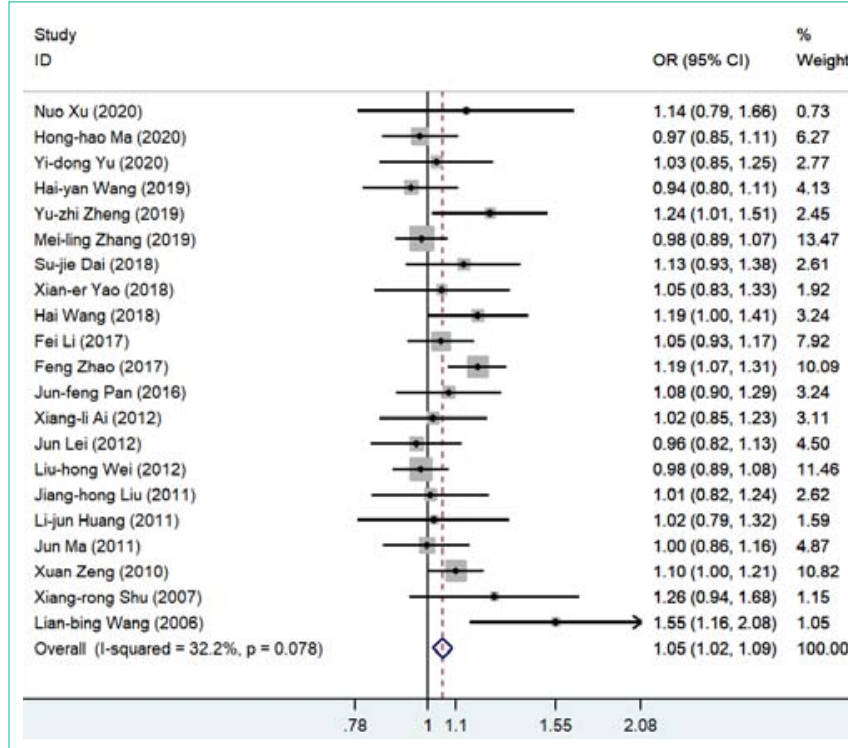

Figure 3: Meta-analysis of zinc deficiency rate in different gender forest plot.

rate of children in mainland China is $27.0 \%$ (95\% CI: $22.8 \%$ to $31.3 \%$ ) (Figure 2).

According to the different regions of the study, different detection equipment of serum zinc and the quality of the research literature, the subgroup analysis was carried out, and the results were found to be significantly heterogeneous. The random effects model was used to merge the effect size (Table 2).

Subgroup analysis according to regional grouping: There are 18 studies with a total of 137641 cases of children in coastal areas and 37 studies with a total of 155,236 cases of children in inland areas. The meta-analysis results show that the zinc deficiency rate of children in coastal areas is $21.7 \%$ (95\% CI: $16.2 \%$ to $27.1 \%$ ), which is lower than that in inland areas. The rate of zinc deficiency in children was $29.6 \%$ (95\% CI: $24.9 \% ~ 34.4 \%$ ); further meta-regression analysis showed that $\mathrm{t}=-2.34, \mathrm{p}=0.023$, the difference was statistically significant, suggesting that different regional factors may be one of the sources of 
Table 2: Subgroup analysis of zinc deficiency rates in Chinese children.

\begin{tabular}{|c|c|c|c|c|c|c|c|c|}
\hline \multirow{2}{*}{ Subgroup Factors } & \multirow{2}{*}{$\begin{array}{c}\text { Number of Research } \\
\text { Documents }\end{array}$} & \multirow{2}{*}{ Sample Size } & \multicolumn{2}{|c|}{$\begin{array}{l}\text { Heterogeneity Test } \\
\text { Results }\end{array}$} & \multicolumn{3}{|c|}{ Meta-analysis Results } & \multirow{2}{*}{ Effect Model } \\
\hline & & & $\mathrm{I}^{2}(\%)$ & $\mathbf{P}$ & $\begin{array}{c}\text { Zinc Deficiency Rate } \\
\text { (\%) }\end{array}$ & $95 \% \mathrm{Cl}$ & $\begin{array}{l}\text { Regression } \\
\text { (P) }\end{array}$ & \\
\hline \multicolumn{9}{|l|}{ Area } \\
\hline Coastal & 18 & 137641 & 99.8 & 0.000 & 21.7 & $0.162-0.271$ & 0.023 & Random \\
\hline Inland & 37 & 119022 & 99.9 & 0.000 & 29.6 & $0.249-0.344$ & - & Random \\
\hline${ }^{*} \mathrm{BH}$ & 35 & 164768 & 99.9 & 0.000 & 28.4 & $0.234-0.334$ & 0.658 & Random \\
\hline MB-5 & 6 & 16274 & 98.2 & 0.000 & 22.1 & $0.226-0.336$ & - & Random \\
\hline${ }^{*}$ Other & 14 & 111835 & 99.9 & 0.000 & 25.7 & $0.179-0.335$ & 0.89 & Random \\
\hline \multicolumn{9}{|l|}{$\begin{array}{l}\text { Research quality } \\
\text { score }\end{array}$} \\
\hline High & 3 & 6890 & 99.8 & 0.000 & 34.3 & $0.083-0.603$ & - & Random \\
\hline Low & 15 & 63969 & 99.7 & 0.000 & 22.9 & $0.171-0.287$ & 0.623 & Random \\
\hline
\end{tabular}

“Note: BH: Include BH2100, BH5100, BH5100plus, BH5300, BH5500, BH5800, BH7100, BH7100s; Others: Include Au5800, ICP-MS, QL8000, AA7001M, AA-7010, ICPQ-1012, PES100, WL-3.

heterogeneity of the meta-analysis.

Subgroup analysis according to different testing instruments: There were 35 studies with a total of 164768 cases using Beijing Bohui $(\mathrm{BH})$ series type number testing equipment, 6 studies with a total of 16,274 cases using Beijing Puxi (MB-5) type testing equipment, and 14 studies with a total of 111835 cases using other brand testing equipment for children undergoing serum zinc examination. The results of meta-analysis indicated that the zinc deficiency rates of the three subgroups were: $28.4 \%$ of children in the $\mathrm{BH}$ group, and children in the MB-5 group. The rate was $22.1 \%$, and the zinc deficiency rate of children in other groups was $25.7 \%$; further meta-regression analysis showed that the $\mathrm{BH}$ group $\mathrm{t}=0.44, \mathrm{p}=0.658$, other groups $\mathrm{t}=-0.14$, $\mathrm{p}=0.890$, the difference was not statistically significant, indicating that the current research data is not enough to prove that factors of different detection instrument are the source of heterogeneity in this meta-analysis.

Subgroup analysis according to the quality of different research literature: There are 3 research documents with high AHRQ score included totaling 6890 cases, 37 research documents with medium scores included totaling 222018 cases, and 15 research documents with low scores included totaling 63,969 cases. The meta-analysis results show that the zinc deficiency rates of children in the three subgroups are as follows: The zinc deficiency rate of children in the high scores group was $34.3 \%$, the rate of zinc deficiency in children in the middle scores group was $28.1 \%$, and the rate of zinc deficiency in children in the low scores group was $22.9 \%$; further meta-regression analysis showed that the medium scores group $t=-0.92, p=0.363$, the low scores group $\mathrm{t}=-0.49, \mathrm{p}=0.623$, the difference was not statistically significant, suggesting the current research literature quality factors are not a source of heterogeneity in this meta-analysis.

Comparison of zinc deficiency rates among children of different genders: There are 21 literatures reported on the zinc deficiency rates in the male and female groups. A total of 83,952 children were included, of which 47,162 were in the male group and 36,790 were in the female group. Meta-analysis was performed. The results are as following (Figure 3).

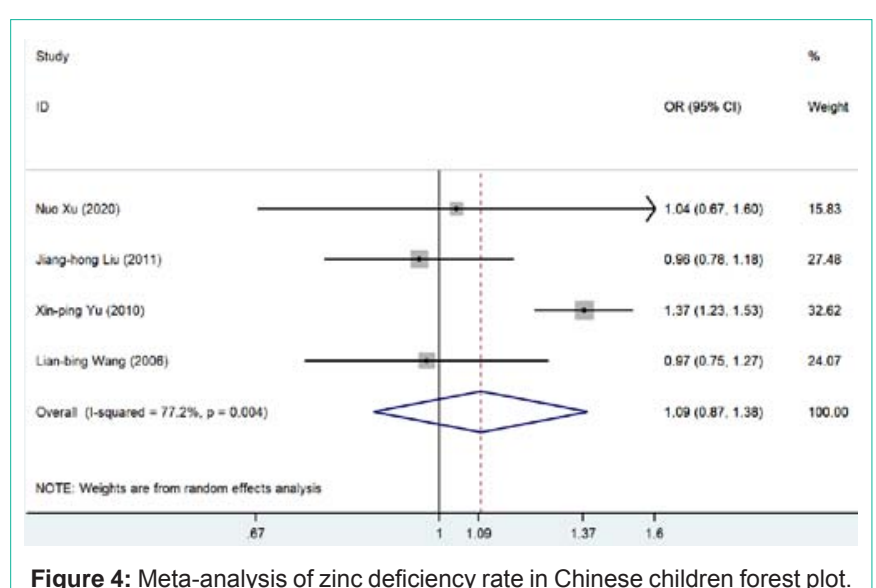

Figure 4: Meta-analysis of zinc deficiency rate in Chinese children forest plot.

The result of heterogeneity test showed that $\mathrm{p}=0.078, \mathrm{I}^{2}=32.2 \%$, there is a certain degree of heterogeneity, using fixed-effects model analysis, Meta-analysis results show that the male group zinc deficiency rate is higher than the female group, the difference is statistically significant [OR=1.052, 95\% CI $(1.019,1.087), \mathrm{p}=0.002]$. Using one-by-one elimination sensitivity analysis, in which Zhao Feng [28] and Wang Lian-bing [61] were eliminated, the results of the heterogeneity test decreased (P value and I2 were: $0.188 / 22.0 \%$; $0.210 / 20.1 \%$, respectively). After excluding two studies of Zhao Feng [28] and Wang Lian-bing [61] at the same time, it was found that the heterogeneity decreased significantly $(\mathrm{p}=0.543, \mathrm{I} 2=0)$. Consider these two studies as the main source of heterogeneity, but through intensive reading literature analysis still cannot confirm the exact reasons for the heterogeneity.

Comparison of zinc deficiency rates among children of different age groups: This study is divided into infant group $(0 \sim 1$ years old), toddler group (1 3 years old), preschool group ( $3 \sim 7$ years old), and school-age children and adolescent group (7 14 years old) according to different ages. Meta-analysis of zinc deficiency rates in age groups (Table 3 ).

Note: The comparison of zinc levels uses Standardized Mean 
Table 3: Meta-analysis for different age groups.

\begin{tabular}{|c|c|c|c|c|c|c|c|c|}
\hline \multirow{2}{*}{$\begin{array}{c}\text { Comparison of Zinc Deficiency Rates in } \\
\text { different Age Groups }\end{array}$} & \multirow{2}{*}{$\begin{array}{l}\text { Number of Research } \\
\text { Documents }\end{array}$} & \multirow{2}{*}{ Sample Size } & \multicolumn{2}{|c|}{$\begin{array}{l}\text { Heterogeneity Test } \\
\text { Results }\end{array}$} & \multicolumn{3}{|c|}{ Meta-analysis Results } & \multirow{2}{*}{$\begin{array}{l}\text { Effect } \\
\text { Model }\end{array}$} \\
\hline & & & $I^{2}(\%)$ & OR & $95 \% \mathrm{Cl}$ & $\mathbf{P}$ & $\begin{array}{l}\text { Regression } \\
\text { (P) }\end{array}$ & \\
\hline Infants group vs. Toddler group & 31 & $37137 / 72923$ & 95.6 & 0.000 & 1.38 & $1.160 \sim 1.60$ & 0.000 & Random \\
\hline Infants group vs. Preschool group & 30 & $35411 / 42795$ & 96.7 & 0.000 & 1.475 & $1.163 \sim 1.870$ & 0.001 & Random \\
\hline $\begin{array}{l}\text { Infants group vs. School-age children and } \\
\text { adolescents group }\end{array}$ & 21 & $28348 / 42102$ & 96.9 & 0.000 & 1.746 & $1.257 \sim 2.425$ & 0.001 & Random \\
\hline $\begin{array}{l}\text { Toddler group vs. School-age children and } \\
\text { adolescents group }\end{array}$ & 19 & $54420 / 40923$ & 95.9 & 0.000 & 1.136 & $0.848 \sim 1.523$ & 0.394 & Random \\
\hline $\begin{array}{l}\text { Preschool group vs. School-age children and } \\
\text { adolescents group }\end{array}$ & 23 & $38946 / 45624$ & 96.1 & 0.000 & 0.986 & $0.754 \sim 1.291$ & 0.919 & Random \\
\hline
\end{tabular}

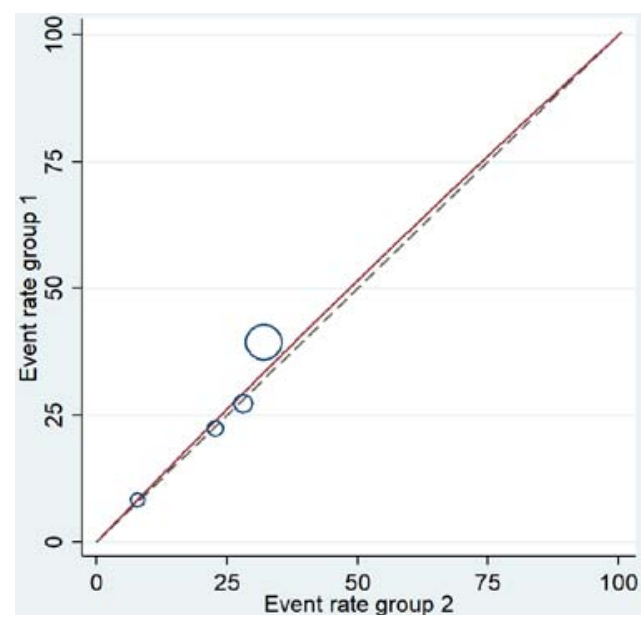

Figure 5: Labbe plot of Heterogeneity Evaluation of Different Educational Levels of Dietary Providers.

Difference (SMD) as the effect value; the comparison of zinc deficiency rates uses the Odds Ratio (OR) as the effect value.

Comparison of trace zinc deficiency rates between infant group and toddler group: There are 31 literatures reporting the values of zinc deficiency rates in infant group and infants. Meta-analysis was performed. The results are as follows: Heterogeneity test $\mathrm{p}=0.000$, $\mathrm{I}^{2}=95.6 \%$, there is a significant heterogeneity, using random-effects model analysis, Meta-analysis results showed that the zinc deficiency rate in the infant group was higher than that in the infant group, and the difference was statistically significant $[\mathrm{OR}=1.38,95 \% \mathrm{CI}$ $(1.16,1.64), \mathrm{p}=0.000]$. The sensitivity analysis was eliminated one by one, and the heterogeneity and analysis results did not change significantly. According to the analysis of subgroups in coastal and inland areas, the results show that in coastal areas, $\mathrm{OR}=1.530,95 \%$ CI $(1.009,2.320), \mathrm{p}=0.045$; inland areas $\mathrm{OR}=1.299,95 \%$ CI $(1.113$, 1.515), $\mathrm{p}=0.001$, Suggesting that the zinc levels of infant group and toddler group in coastal areas and inland areas are lower than infant group, and the difference is statistically significant. Further Meta regression analysis, $\mathrm{t}=-0.82, \mathrm{p}=0.42$, the difference was not statistically significant, suggesting that regional factors of the existing research data are not the main source of the heterogeneity.

Comparison of zinc deficiency rate between infant group and preschool group: There are 30 literatures reporting the values of zinc deficiency rates in the infant group and preschool group. Meta- analysis was performed. The results are as follows: heterogeneity test $\mathrm{p}=0.000, \mathrm{I}^{2}=96.7 \%$, there is a significant heterogeneity, using randomeffects model analysis, Meta-analysis showed that the zinc deficiency rate in the infant group was higher than that in the preschool group, and the difference was statistically significant $[\mathrm{OR}=1.475,95 \% \mathrm{CI}$ $(1.163,1.870), \mathrm{p}=0.001]$. The sensitivity analysis was eliminated one by one, and the heterogeneity and analysis results did not change significantly. According to the analysis of subgroups in coastal and inland areas, the results showed that in coastal areas, $\mathrm{OR}=2.278$, $95 \%$ CI $(1.348,3.849), p=0.002$, suggesting that the zinc deficiency rate in the infant group in the coastal area is higher than that in the preschool group, and the difference is statistically significant. Significance: $\mathrm{OR}=1.228,95 \%$ CI $(0.959,1.574), \mathrm{p}=0.104$ in the inland area, suggesting that there is no statistically significant difference in the zinc deficiency rate between the infant group in the inland area and the preschool group. Further Meta regression analysis, $t=-1.91$, $\mathrm{p}=0.42$, the difference was not statistically significant, suggesting that regional factors of the existing research data are not the main source of the heterogeneity.

Comparison of zinc deficiency rates between infant group and school-age children and adolescents: There are 21 literatures reporting the values of the zinc deficiency rate in the infant group and school-age children and adolescents. Meta-analysis was performed. The results are as follows: Heterogeneity test $\mathrm{p}=0.000, \mathrm{I}^{2}=96.9 \%$, there is a large heterogeneity, and the random effects model is used for analysis, The results of Meta-analysis showed that the zinc deficiency rate in the infant group was higher than that in the school-age children and adolescent group, and the difference was statistically significant [OR $=1.746,95 \%$ CI $(1.257,2.425), \mathrm{p}=0.001]$. The sensitivity analysis was eliminated one by one, and the heterogeneity and analysis results did not change significantly. According to the analysis of subgroups in coastal and inland areas, the results show that in coastal areas, $\mathrm{OR}=4.203,95 \% \mathrm{CI}(2.425,7.284), \mathrm{p}=0.000$, suggesting that the zinc deficiency rate of infants in coastal areas is higher than that of school-age children and adolescents, and the difference is statistically significant. Scientific significance: $\mathrm{OR}=1.321,95 \%$ CI $(0.922,1.894)$, $\mathrm{p}=0.104$ in the inland area, suggesting that there is no statistically significant difference in the zinc deficiency rate between the infant group in the inland area and the school-age children and adolescents. Further Meta regression analysis, $\mathrm{t}=-2.42, \mathrm{p}=0.026$, the difference is statistically significant, suggesting that regional factors may be one of the sources of heterogeneity.

Comparison of zinc deficiency rates between the toddler group 
and the preschool group: There are 33 literatures reporting the values of zinc levels and zinc deficiency rates in the toddler group and the preschool group. Meta-analysis was performed. The results are as follows: Heterogeneity test $\mathrm{p}=0.000, \mathrm{I}^{2}=92.7 \%$, there is large heterogeneity, random effects are used Model analysis and Metaanalysis showed that there was no statistically significant difference in the zinc deficiency rate between the infant group and the preschool group [OR $=1.059,95 \%$ CI $(0.918,1.222), \mathrm{p}=0.429]$. The sensitivity analysis was eliminated one by one, and the heterogeneity and analysis results did not change significantly. According to the analysis of subgroups in coastal and inland areas, the results showed that in coastal areas, $\mathrm{OR}=1.341,95 \% \mathrm{CI}(1.092,1.647), \mathrm{p}=0.005$, suggesting that the zinc deficiency rate of children in coastal areas is higher than that in preschool groups, and the difference is statistically significant. the results show that in the inland area: OR $=0.938,95 \%$ CI $(0.779$, 1.129), $\mathrm{p}=0.496$, suggesting that there is no statistically significant difference in the zinc deficiency rate between the inland children group and the preschool group. Further Meta regression analysis, $\mathrm{t}=2.11, \mathrm{p}=0.043$, the difference is statistically significant, suggesting that regional factors may be one of the sources of heterogeneity.

Comparison of zinc deficiency rates between the toddler group and school-age children and adolescents: There are 19 literatures reporting the values of zinc levels and zinc deficiency rates in the toddler group and school-age children and adolescents. Metaanalysis was performed. The results are as follows: Heterogeneity test $\mathrm{P}=0.000, \mathrm{I}^{2}=95.9 \%$, there is a large heterogeneity, randomized Effect model analysis, the results of Meta-analysis showed that there was no statistically significant difference in the zinc deficiency rate between the infant group and school-age children and adolescents [OR $=1.136,95 \%$ CI $(0.848,1.523), p=0.394]$. The sensitivity analysis was eliminated one by one, and the heterogeneity and analysis results did not change significantly. According to the analysis of subgroups in coastal and inland areas, the results show that in coastal areas, $\mathrm{OR}=1.564,95 \% \mathrm{CI}(1.034,2.365), \mathrm{p}=0.034$, suggesting that the zinc deficiency rate in the coastal area is higher than that of school-age children and adolescents, and the difference is statistically significant. The results show that in the inland area: $\mathrm{OR}=1.049,95 \%$ CI $(0.715$, 1.537), $\mathrm{p}=0.857$, suggesting that there is no statistically significant difference in the zinc deficiency rate between the inland children group and the preschool group. Further META regression analysis, $\mathrm{t}=1.42$, $\mathrm{p}=0.174$, the difference was not statistically significant, suggesting that regional factors are not the main source of heterogeneity.

Comparison of zinc deficiency rates between preschool group and school-age children and adolescents: There are 23 literatures reporting the values of zinc levels and zinc deficiency rates in the infant group and school-age children and adolescents. Meta-analysis was performed. The results are as follows: heterogeneity test $\mathrm{P}=0.000$, $\mathrm{I}^{2}=96.1 \%$, there is a large heterogeneity, and randomized Effect model analysis, the results of Meta-analysis showed that the preschool group and school-age children and adolescents' group of zinc deficiency rates were not statistically different $[\mathrm{OR}=0.986,95 \% \mathrm{CI}(0.754,1.291)$, $\mathrm{P}=0.919]$. The sensitivity analysis was eliminated one by one, and the heterogeneity and analysis results did not change significantly. According to the analysis of subgroups in coastal and inland areas, the results show that in coastal areas, $\mathrm{OR}=0.838,95 \% \mathrm{CI}(0.610,1.151)$, $\mathrm{P}=0.275$, suggesting that there is no difference in the zinc deficiency

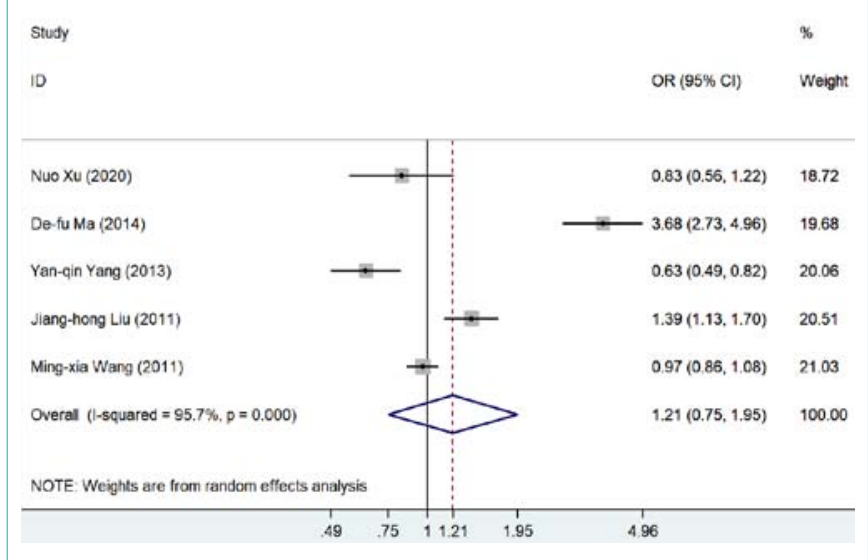

Figure 6: Forest plot comparing zinc deficiency rate between urban group and rural group.

rate between the preschool group and the school-age children and adolescents in the coastal area. Statistical significance; $\mathrm{OR}=1.067$, $95 \%$ CI $(0.740,1.540), \mathrm{p}=0.728$ in the inland area, suggesting that there is no statistically significant difference in the zinc deficiency rate between the preschool group in the inland area and the school-age children and adolescents. Further Meta regression analysis, $t=-1.03$, $\mathrm{p}=0.313$, the difference was not statistically significant, suggesting that regional factors are not the main source of heterogeneity.

Comparison of zinc deficiency rates among children with different influencing factors: In this study, 4 literatures reported that the zinc deficiency rate of different educational level factors of diet providers totaled 7406 children, of which 4112 were in the high-education group and 3294 were in the low-education group. Another 5 articles reported on urban areas. The influencing factors of zinc deficiency in rural areas totaled 10,497 children, including 6,875 in the urban group and 3,622 in the rural group. Meta-analysis was performed. The results are as follows:

Comparison of zinc deficiency rates among children with different education levels among diet providers: In this study, the educational level of dietary providers (mainly mothers) was divided into high educational level (high school, technical secondary school, college and above) and low educational level (junior high school and below). The heterogeneity test results showed that $\mathrm{p}=0.004, \mathrm{I}^{2}=77.2 \%$, there is a large heterogeneity, using random effects model analysis, the meta-analysis results show that there is no statistically significant difference in the zinc deficiency rate between the diet provider's higheducation group and the low-education group $[\mathrm{OR}=1.095,95 \% \mathrm{CI}$ (0.867, 1.383), $\mathrm{p}=0.446$ ] (Figure 4).

Using one-by-one elimination sensitivity analysis, the study by Yu Xinping [53] was eliminated. The results showed that the heterogeneity test $\mathrm{P}=0.946, \mathrm{I}^{2}=0$, and the heterogeneity decreased significantly, suggesting that this study may be the main source of heterogeneity. The Labbe test for heterogeneity evaluation was further performed, and the result graph showed that the study deviated from the valid line (Figure 5).

But by reading the literature in detail, the reason for the heterogeneity was not found. Using fixed effects model analysis, the difference was not statistically significant $[\mathrm{OR}=0.972,95 \% \mathrm{CI}(0.834$, 


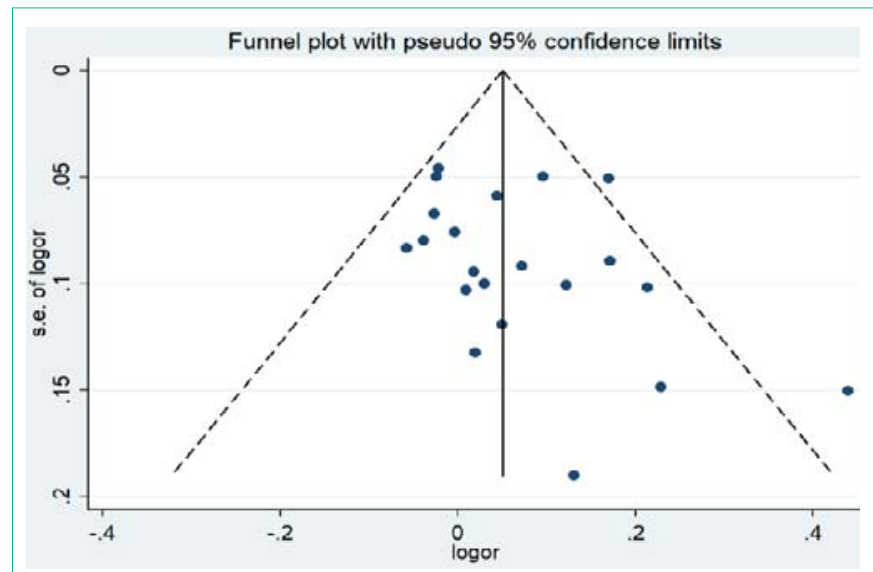

Figure 7: Funnel plot comparison of zinc deficiency rate between male group and female group.

1.133), $\mathrm{p}=0.719$ ], the results of the Meta-analysis did not change.

Comparison of zinc deficiency rates among children in different urban and rural areas: The heterogeneity test results show that $\mathrm{I}^{2}=95.1 \%, \mathrm{p}=0.000$, there is a large heterogeneity, using random effects model analysis, Meta-analysis results show that the urban group zinc deficiency rate compared with the rural group, the difference is not statistically significant $[\mathrm{OR}=1.152,95 \%$ CI $(0.810$, 1.637), $\mathrm{p}=0.432$ ] (Figure 6). The sensitivity analysis was eliminated one by one, and the results of heterogeneity and Meta-analysis did not change significantly.

Publication bias: Meta-analysis of the rates of zinc deficiency in the male and female groups was conducted to test the publication bias in a funnel plot. Funnel plots were roughly symmetrical (Figure 7), indicating that the publication bias was less likely; the Egger test was further analysis, and the results showed that there was no statistically significant difference in publication bias $(\mathrm{t}=1.43, \mathrm{p}=0.168)$.

\section{Discussion}

Zinc is a mineral that is very important to human health, and it is an essential trace element distributed throughout the body. According to the concept of type I/II nutrient proposed by $\mathrm{M}$. Golden [62], zinc belongs to type II nutrient, and type II nutrient can be regarded as a "growth nutrient", that is, a type of nutrient that is essential for growth. In the state, cell growth will stop. Zinc is distributed in all organs, tissues, body fluids and secretions in the human body. Most of the zinc is located in non-fat tissues. Among them, the zinc in skeletal muscle and skeletal tissue accounts for $83 \%$ of the total body zinc [63], and more than $95 \%$ of zinc is in the cells inside. When zinc-containing foods or drugs are ingested, zinc is released into the intestine in the form of zinc ions, and combines with endogenous secretory ligands or exogenous substances in the intestinal lumen, in the distal duodenum and jejunum The proximal absorption and transport enter the portal venous system, and then are rapidly absorbed in the liver and released into the systemic circulation for transport to other tissues [64]. Circulating serum zinc only accounts for $0.1 \%$ of body zinc, and about $70 \%$ of serum zinc is bound to albumin, so any condition that changes the serum albumin concentration will affect the serum zinc level [65]. Zinc excretion in the body is mainly excreted through the intestine, which accounts for about $50 \%$. Other ways include urine, which accounts for about $15 \%$ of the total loss of zinc; epithelial cell shedding, sweat, semen, hair and menstrual blood account for about $17 \%$ of the total loss of zinc [66].

Zinc is involved in cell division and growth, intestinal electrolyte absorption, neurotransmission, immune response, enzyme catalysis or stabilization, and functional modification of membrane proteins, gene regulatory proteins and hormone receptors [67-69]. Through these pathways, zinc plays a very important role in the synthesis of DNA and RNA, protein metabolism, and overall growth and development [69]. In view of the various biological functions of zinc, the state of zinc in the body affects various physiological and metabolic functions, such as body growth [70,71], immune function $[72,73]$, reproductive function and neurobehavioral development $[74,75]$. The clinical manifestations of zinc deficiency in children and adolescents of different ages are different $[76,77]$. In neonates, infants, toddlers and preschool children, zinc deficiency is mostly manifested as cognitive impairment, behavioral and emotional changes, etc. In severe zinc deficiency, limb or perioral skin lesions can be seen; zinc deficiency in school-age children can be Manifested as growth retardation, blepharon conjunctivitis, hair loss and repeated infections; adolescent zinc deficiency can lead to delayed sexual maturity [78].

PZC is currently recognized as the best available biomarker for the risk of zinc deficiency in the population. When the prevalence of low PZC in children is more than $20 \%$, it is considered that there is an increased risk of zinc deficiency, which requires public health attention.

The main basis for choosing PZC as a biomarker of zinc deficiency in the population is that PZC can reflect the dietary zinc intake; its response to zinc supplementation is consistent, the prevalence of low PZC and the prevalence of insufficient dietary zinc intake. There is agreement between [79], and most age and gender groups have reference data. However, PZC is easily affected by factors such as recent meals, time of day, age, gender, and systemic infection or inflammation. Studies have shown that PZC fluctuates up to $20 \%$ a day, mainly due to the amount of meals, usually the highest concentration can be observed before clearing breakfast [80]. Therefore, at the individual level, the correlation between PZC and zinc intake is very poor, and it is currently not recommended to use this indicator to diagnose and treat individuals. In addition, since the collected samples are easily contaminated by the surrounding zinc sources, appropriate precautions must be taken during the collection, processing and analysis of the samples to avoid contamination. At present, the lower limit of plasma (or serum) for children under 10 years of age is set at $65 \mu \mathrm{g} / \mathrm{dL}(9.9 \mu \mathrm{mol} / \mathrm{L})[81,82]$. In China, a trace amount of whole blood zinc is more commonly used as a method for detecting zinc content. Because of the small amount of blood taken, it is easier to be accepted by children and parents. In general, except for elements that are not suitable for serum detection, most trace elements have little difference in serum and whole blood, and their absolute values are not the same, but they can all reflect the zinc status of the human body [78].

Zinc deficiency is an important cause of the disease in developing countries, especially infants and young children, but there is little 
information about the global prevalence of zinc deficiency. According to reports, nearly one-fifth (17\%) of the world's population is at risk of zinc deficiency, with Asia and Africa having the highest prevalence [83,84]. Hess SY [85] analyzed 20 survey reports in 2017 and concluded that in 13 of 19 surveys, the prevalence of plasma (or serum) zinc levels (PZC) in children below the normal value was greater than $20 \%$, among which the prevalence of low PZC among young children in Cameroon is as high as $83 \%$ [86], 68\% in Cambodia [87], and the prevalence of low PZC among young children in Kenya, Senegal, South Africa and Vietnam is about 50\% [88-91]. The prevalence of low PZC among young children in Latin American countries ranges from $27 \%$ to $43 \%$ [92-95]. Only Afghanistan, Azerbaijan, Nigeria, the Republic of Maldives, Sri Lanka and China have prevalence of low PZC in young children less than 20\% [96-100]. The results of 20 countries indicate that zinc deficiency is a public health problem in most of these countries, and zinc intervention strategies should be considered. Due to the vast territory of China, there are obvious differences in the status of zinc deficiency. A survey of 3069 children and adolescents aged 0-17 years from 2016 to 2018 in Zhoushan City, Zhejiang Province from Wang Haiyan et al. [11] showed that the overall zinc deficiency rate was 23.23\%; Wang Junwen et al. [16] reported The overall zinc deficiency rate of 14,569 children and adolescents aged 0-17 years in Jiangyou City, Sichuan Province was $11.49 \%$ in 2016-2018; Zhao Feng et al. [28] reported that 16683 children and adolescents aged 0-7 years in Fuzhou City, Fujian Province had a total zinc deficiency rate of $11.49 \%$ in 20162017. The overall zinc deficiency rate was $21.75 \%$.

The results of this study showed that the overall zinc deficiency rate of children aged $0-14$ were $27.0 \%$ (95\% CI $22.8 \%-31.3 \%$ ). It can be seen that overall zinc deficiency among children aged $0-14$ years in mainland China is still relatively common. According to the analysis of different subgroups in the coastal and inland areas, the results show that the zinc deficiency rate in the coastal area group is lower than that in the inland area group. This may be related to the more seafood food components in the coastal area's diet and the higher zinc content in seafood foods. The comparison of the zinc nutritional status of children of different genders showed that there was no statistical difference in the total blood zinc levels of children in the male group and the female group, while the zinc deficiency rate in the male group was higher than that in the female group, and the difference was statistically significant $[\mathrm{OR}=1.052,95 \% \mathrm{CI}(1.019,1.087), \mathrm{p}=0.002]$, the reason may be related to the differences between different regions. The comparison of zinc nutrition status among different age groups showed that the trace levels of whole blood zinc in the infant group, toddler group, and preschool group increased in turn. It can be seen that blood zinc levels gradually increase with age. The possible reasons are with age, the diet becomes more diverse and exposure to foods with high zinc content is more abundant. In contrast to the zinc deficiency rate, the infant group has the highest zinc deficiency rate. The possible reason is that the infant's diet is mainly breast milk, and exclusively breastfed infants can meet their zinc requirements for the first 5-6 months after birth [101], experimental evidence. This is well supported [102-105]. However, after about 6 months of age, breast milk alone cannot provide enough zinc to meet the needs of infants $[101,106]$. Therefore, if the time of supplementing breastfeeding infants with food is postponed until after six months of age, or if the supplementary food contains insufficient absorbable zinc, the risk of zinc deficiency in infants will be greatly increased.

The results of this meta-analysis showed that there was no statistical difference in the impact of dietary providers on zinc deficiency in children [OR=1.095, 95\% CI $(0.867,1.383), \mathrm{p}=0.446]$, but the sample size included in the study was small. Jianghong Liu et al. [42] reported that the children of mothers with higher education are at a lower risk of zinc deficiency compared with those of mothers with lower education levels; Yu Xinping et al. [53] reported that the dietary providers are highly educated. Parents may pay more attention to children's health, can seek more scientific knowledge of parenting, and can arrange children's meals reasonably, which is conducive to reducing the prevalence of children's zinc deficiency. The impact of different factors in urban and rural areas on children's zinc deficiency, the results of Meta-analysis showed that the difference was not statistically significant $[\mathrm{OR}=1.152,95 \% \mathrm{CI}(0.810,1.637)$, $\mathrm{p}=0.432$ ]. Jianghong Liu et al. [42] reported that the serum zinc level of rural preschool children was lower than that of urban children; and Ma Defu et al. [32] reported that the detection rate of zinc deficiency in first-tier cities and second-tier cities was significantly higher than that in plain towns and mountainous towns. Different from previous reports, the study found that this may be related to the more common zinc nutritional supplement intake in plain towns and mountain towns in the region. The results of this meta-analysis also did not show the differences in the rates of zinc deficiency among children in different urban and rural areas, and more studies are still needed for further analysis.

\section{Conclusion}

At present, the zinc deficiency of children aged 0-14 in mainland China is still severe, especially in infancy; the zinc deficiency rate of male children is higher than that of female children; the zinc deficiency rate of children in inland areas is higher than that in coastal areas; diet provider culture Factors such as different levels and different urban and rural areas are not the main influencing factors of zinc deficiency. These have certain reference significance for assessing the status of zinc deficiency in mainland China and how to improve zinc nutrition.

\section{Acknowledgments}

We would like to express our gratitude and appreciation to our colleagues in the Department of pediatrics XingLin branch, the first affiliated hospital of Xiamen University for their help. Again, we would like to acknowledge participants of the studies and the authors of the studies included in this systematic review and meta-analysis.

\section{Authors' Contributions}

Yan CJ involved in study design, selection of articles, data extraction, summarizing and synthesizing findings, and manuscript writing. Similarly, Su JY and Lin GX involved in study design, selection of articles, data extraction, summarizing and synthesizing findings, and manuscript writing. All authors read, revised and approved the final draft of the manuscript.

\section{Availability of Data and Materials}

All data regarding this meta-analysis are contained and presented 
in this meta-analysis document.

\section{References}

1. Prasad AS, Miale AJ, Farid Z, Sandstead HH, Schulert AR. Zinc metabolism in patients with the syndrome of iron deficiency anemia, hepatosplenomegaly, dwarfism, and hypogonadism. J Lab Clin Med. 1963; 61: 537-549.

2. Hambidge M. Human zinc deficiency. J Nutr. 2000; 130: 1344S-1349S.

3. Moynahan EJ. Letter: Acrodermatitis enteropathica: a lethal inherited human zinc-deficiency disorder. Lancet. 1974; 2: 399-400.

4. Black RE, Victora CG, Walker SP, et al. Maternal and Child Nutrition Study Group. Maternal and child undernutrition and overweight in low-income and middle-income countries. Lancet. 2013; 382: 427-451.

5. Fischer Walker CL, Ezzati M, Black RE. Global and regional child mortality and burden of disease attributable to zinc deficiency. Eur J Clin Nutr. 2009; 63: 591-597.

6. Rostom A, Dube C, Cranney A, et al. Celiac Disease. Rockville (MD): Agency for Healthcare Research and Quality (US); 2004.

7. Xu N, Zhang GB, Xie GD, et al. The relationship between dietary behavior and nutritional status of school-age children and their gender differences. Chinese Public Health. 2020; 36: 1271-1277.

8. Zhang RZ, Chen Q, Guo SY. The levels of lead, calcium, zinc, copper, magnesium and iron in the whole blood of preschool children in Longhua District, Shenzhen. Journal of Environmental Hygiene. 2020; 10: 306-310.

9. Ma HH, Luo H, Li H, et al. Trace elements and nutritional status of preschool children in Guangzhou area. Public Health and Preventive Medicine. 2020; 31: 88-91.

10. Yu YD, Feng W, Ye SD. Investigation and analysis of the levels of 6 elements in the whole blood of children in Cixi, Zhejiang Province from 2018 to 2019 Disease Surveillance. 2020; 35: 845-849.

11. Wang HY, Hong KT, Si ST, et al. Analysis of 5 trace elements in peripheral blood of children aged 0-17 years in Zhoushan City, Zhejiang Province. Chinese Journal of Health Inspection. 2019; 29: 2910-2914.

12. Zhang $\mathrm{X}, \mathrm{Li} \mathrm{YH}, \mathrm{Li} \mathrm{Y}$, et al. Analysis on the relationship between trace elements zinc, iron, copper and dietary nutrition in infants and young children in poverty-stricken minority areas in Yunnan. Journal of Kunming Medical University. 2019; 40: 24-29.

13. Zeng $\mathrm{CF}$, Huang $\mathrm{H}$, Peng $\mathrm{CJ}$, et al. Investigation and analysis of trace element detection results in the whole blood of 3079 children aged 0-7 years in Shenzhen. Chinese and Foreign Medical Research. 2019; 17: 186-188.

14. Zheng YZ, Cao LJ, Liu YY, et al. Analysis of trace and macro element detection results of 4618 infants and children aged 0 to 3 years in Tianjin. China Maternal and Child Health Care. 2019; 34: 88-90.

15. Zhang ML. Investigation and analysis of blood zinc levels in children aged 0 to 5 years in a certain area of Yunnan. Systems Medicine. 2019; 4: 87-89.

16. Wang JW, Chen W. Tracking analysis of trace element deficiency in whole blood of children and adolescents in Jiangyou area from 2016 to 2018 Journal of Practical Laboratory Medicine. 2018; 10: 226-229.

17. Dai SJ, Li Wen, Yang WK, et al. Analysis of trace element content in infants aged 0-12 months in Lanzhou City. Medical Journal of National Defense of Northwest China. 2018; 39: 794-799.

18. Yao XE, Hong KT, Wu JH, et al. Analysis of the whole blood zinc, calcium, iron, magnesium and copper contents of children in kindergartens in Zhoushan area in 2016. Chinese Journal of Health Inspection. 2018; 28 3034-3035+3039.

19. Wang ZW, Li Z, Zuo Y, et al. Investigation of peripheral blood copper, zinc, calcium, magnesium, iron and lead levels in children in Lianyungang City. Preventive Medicine. 2018; 30: 949-952.

20. Wang $\mathrm{H}$, Zhou $\mathrm{L}$, Liu Q et al. Analysis of trace element detection results of 2236 preschool children in Hangzhou. Chinese General Practice. 2018; 16: 974-976.
21. Xiang LL, Liu JQ, Pan XQ, et al. Analysis of Zinc Test Results and Deficiency Rate of Children in Zhejiang Province. Research on Trace Elements and Health. 2018; 35: 23-26.

22. Zheng JZ. 5621 children with trace element deficiency and its prevention Clinical Medical Research and Practice. 2018; 3: 120-121.

23. Deng JS, Pu ZY, Li XK. Analysis of the results of whole blood zinc content in people of different ages. Medical Information. 2018; 31: 128-130.

24. Yang $Y$, Liu $X Y$. Analysis of 5 trace elements and influencing factors in whole blood of children in Datong area. Journal of Shanxi Datong University (Natural Science Edition). 2017; 33: 60-63.

25. Zhu YT, Wang XM, Xiang LL. Investigation and analysis of trace elements in 2502 children from 1 to 7 years old in Nanjing area. Chinese Continuing Medical Education. 2017; 9: 50-52.

26. Zhang WJ. Investigation and analysis of blood zinc, iron, copper and calcium levels in 1646 healthy children. Chinese Journal of Reproductive Health. 2017; 28 : 35-37+41.

27. Li Fei, Li Fei, Huang LC, et al. Analysis of trace element levels in 6146 children in Tangxia Town. Journal of Shantou University Medical College. 2017; 30: 164+168.

28. Zhao Feng, $\mathrm{Wu} Z \mathrm{ZH}, \mathrm{Xu}$ LP. Discussion on the determination results of copper, zinc, calcium, magnesium and iron in the peripheral blood of preschool children. Journal of Practical Medical Techniques. 2017; 24: 12131215.

29. Pan JF, Liu YY, Zhang J, et al. Detection and analysis of 6 trace elements in preschool children in Haozhou City. Laboratory Medicine and Clinics. 2016; 13: $1250-1252$.

30. Du CR, Huang Y, Yang QL, et al. Analysis of trace and macro element results of children in Fengtai, Beijing . China Medical Herald. 2016; 13: 93-95.

31. Zhai KQ, Zhang LN. Investigation on blood zinc levels of preschool children in Kaifeng area. Chinese Modern Doctor. 2015; 53: 93-95.

32. Ma DF, Zhang YM, Wang PY, et al. Investigation on blood mineral levels of children aged 3-12 years in 7 cities and 2 towns in China. Journal of Peking University (Health Sciences). 2014; 46: 379-382.

33. Sun YJ, Zhao WC, Zhang ML, et al. Analysis of detection results of 6 inorganic elements in venous whole blood of children of different ages in Chengde area. International Journal of Laboratory Medicine. 2014; 35: 432 434.

34. Yang Q, Zeng BH, Liu QC, Study on the content of trace elements in peripheral blood of children and their influencing factors. Chinese Medical Journal. 2014; 12: 240.

35. Lu XJ, Li XJ, Peng Y, et al. Analysis of calcium and trace element detection results in children in Fengxian District, Shanghai. International Journal of Laboratory Medicine. 2014; 35: 2328-2329.

36. Yang YQ, Ding JZ. Analysis of blood trace element detection results of children aged 2 to 7 years in Yanping District, Nanping City. Strait Journal of Preventive Medicine. 2013; 19: 40-41

37. Zhao TT, Chen B, Wang HP, et al. Evaluation of toxic and essential elements in whole blood from 0-to 6-year-old children from Jinan, China. Clin Biochem. 2013; 46: 612-616

38. Ai XL, Lin ZQ, Zou D. Analysis of detection results of peripheral blood zinc iron, calcium, magnesium and copper in 1880 children. Chinese Journal of Coal Industry Medicine. 2012; 15: 1516-1519.

39. Lei J, Chen PL. Investigation on finger blood zinc levels of preschool children in Lishui city. Shanghai Preventive Medicine. 2012; 24: 563-564.

40. Wei LH, Fan W, Luo HM, et al. Analysis of blood zinc detection results in 4615 infants. Laboratory Medicine and Clinics. 2012; 9: 2052-2053.

41. Luo HE, Chen WS, Li J, et al. Investigation and analysis of trace elements in 1076 children. Chinese and Foreign Health Digest. 2012: 17-18.

42. Liu J, Ai YX, Hanlon A, et al. Micronutrients deficiency and associated 
sociodemographic factors in Chinese children. World J Pediatr. 2011; 7 217-223.

43. Huang LJ. Investigation of trace element levels in whole blood of children in Hanshou County and analysis of related influencing factors. Practical Preventive Medicine. 2011; 18: 1034-1036.

44. Hou WQ, Hou WF, Zhang GM, et al. Investigation on the levels of trace elements in children of different age groups in Shuyang County. Journal of Mudanjiang Medical College. 2011; 32: 35-37.

45. E JF, Cao LJ, Li J. Analysis of trace elements in blood of 1572 children in Deyang area. Sichuan Medicine. 2011; 32: 760-762.

46. Zhang $Z Q$, Zhang $\mathrm{YH}$, Zhao $\mathrm{B}$, et al. Analysis of the detection results of trace elements in the peripheral blood of preschool children in Chengdu. Guangdong Trace Element Science. 2011; 18: 31-34.

47. Yuan $\mathrm{XH}$, Chen $\mathrm{XL}$, Chen $\mathrm{GZ}$, et al. Investigation and analysis of 7 trace elements in finger blood of preschool children in Shiyan City. Western Medicine. 2011; 23: 992-993.

48. Hong KT, Ma HS, Chen $\mathrm{P}$, et al. Investigation and analysis of the levels of several minerals in children in Zhoushan island area from 2006 to 2010 Environmental and Occupational Medicine. 2011; 28: 760-761+ 764.

49. Shi LJ. Analysis of trace elements in the finger blood of children in the central district of Leshan City. Modern Preventive Medicine. 2011; 38: 2477-2479.

50. Wang MX, SiMa L. Investigation and analysis of trace elements in 5064 children in Leshan City. Chinese Contemporary Medicine. 2011; 18: 145147.

51. Ma J, Shi DG. Analysis of trace elements in peripheral blood of 3,653 preschool children. Chinese Journal of Hemorheology. 2011; 21: 342-344.

52. Zeng $X$, Tang $X Q$, Ding $H H$, et al. Analysis of trace element detection results for infants and children aged 0 to 3 years in Jiangxi. Chinese Maternal and Child Health Care. 2010; 25: 1797-1798.

53. Yu XP, Guo MZ, Sun PH. Analysis of influencing factors of mineral deficiency in children aged 0-6 years in Changchun City. Chinese Journal of Materna and Child Health Research. 2010; 21: 808-811.

54. Zhao ZL, Ma LJ. Analysis of trace element detection results in 1312 children in Miyun. Shandong Medicine. 2010; 50: 71-73

55. Jiang $\mathrm{Y}$, Zhou $\mathrm{H}, \mathrm{Ma} \mathrm{YN}$, et al. Analysis of trace elements in peripheral blood of 1027 children. Journal of Luzhou Medical College. 2010; 33: 666-668.

56. Lian LL, Sun SY, Cao HS. Analysis of trace element content in whole blood of 4750 children aged $0-12$ years in Changchun City. China Maternal and Child Health Care. 2010; 25: 1218-1219.

57. Xue $F$, Luo $H Q$, Ye CY. Analysis on the status quo of the detection results of 5 trace elements in children in Chengdu area. Sichuan Medicine. 2009, 30: $1798-1800$.

58. Liang $\mathrm{Y}, \mathrm{Cao} \mathrm{CH}$, Dong $\mathrm{ZQ}$, et al. Analysis on the levels of 5 elements in the whole blood of 1992 preschool children in Xi'an. Chinese Journal of Child Health Care. 2009; 17: 280+283.

59. Song $W Q, X u X W, L i ~ Q L$, et al. Study on the distribution characteristics and relationship between peripheral blood trace elements and blood lead in children in Beijing area. Chinese Journal of Epidemiology. 2008: 564-568.

60. Shu XG, Ding HH, Zhan XJ. Detection of trace elements in peripheral blood of healthy children in Nanchang area and analysis of related factors. Jiangxi Medical Laboratory Science. 2007: 593-595.

61. Wang LB, Gu DW, Su ZE. Study on trace elements and related factors of preschool children in industrial and mining areas. Chinese Journal of Clinical Medicine. 2006; 007: 129-131.

62. Golden MHN. Malnutrition. In Textbook of Pediatric Gastroenterology and Nutrition; Guandalini S, Ed.; Taylor \& Francis: London, UK. 2004: 489-524.

63. lyengar GV. Reevaluation of the trace element content in reference man. Radiat Phys Chem. 1998; 51: 545-560.

64. Cousins RJ. Zinc. In: Ziegler EE, Filer LJ Jr, eds. Present Knowledge in
Nutrition, $7^{\text {th }}$ ed. Washington, DC: ILSI Press. 1996.

65. King JC, Shames DM, Woodhouse LR. Zinc homeostasis in humans. J Nutr. 2000; 130: 1360S-1366S.

66. Food and Nutrition Board, Institute of Medicine. Die-tary reference intakes of vitamin $\mathrm{A}$, vitamin $\mathrm{K}$, arsenic, boron, chromium, copper, iodine, iron, manganese, molybdenum, nickel, silicon, vanadium, and zinc. Washington, DC: National Academy Press. 2002.

67. King JC. Zinc: an essential but elusive nutrient. Am J Clin Nutr. 2011; 94: 679S-684S.

68. Terrin G, Berni Canani R, Di Chiara M, et al. Zinc in Early Life: A Key Element in the Fetus and Preterm Neonate. Nutrients. 2015; 7: 10427-10446.

69. Wardlaw GM, Hampl JS. Perspectives in Nutrition, $5^{\text {th }}$ ed.; McGraw-Hill: Boston, MA, USA. 2007.

70. Brown KH, Peerson JM, Rivera J, et al. Effect of supplemental zinc on the growth and serum zinc concentrations of prepubertal children: a metaanalysis of randomized controlled trials. Am J Clin Nutr. 2002; 75: 1062 1071.

71. Krebs NF. Update on zinc deficiency and excess in clinical pediatric practice. Ann Nutr Metab. 2013; 62: 19-29.

72. Raiten DJ, Ashour FA, Ross AC, et al; INSPIRE Consultative Group Inflammation and Nutritional Science for Programs/Policies and Interpretation of Research Evidence (INSPIRE). J Nutr. 2015; 145: 1039S-1108S.

73. Fraker PJ, King LE. Reprogramming of the immune system during zinc deficiency. Annu Rev Nutr. 2004; 24: 277-298.

74. Gewa CA, Weiss RE, Bwibo NO, et al. Dietary micronutrients are associated with higher cognitive function gains among primary school children in rural Kenya. Br J Nutr. 2009; 101: 1378-1387.

75. Umamaheswari K, Bhaskaran M, Krishnamurthy G, et al. Effect of iron and zinc deficiency on short term memory in children. Indian Pediatr. 2011; 48: 289-293.

76. Hambidge KM. Zinc deficiency in man: its origins and effects. Philos Trans R Soc Lond B Biol Sci. 1981; 294: 129-144.

77. Corbo MD, Lam J. Zinc deficiency and its management in the pediatric population: a literature review and proposed etiologic classification. $\mathrm{J}$ Am Acad Dermatol. 2013; 69: 616-624.e1.

78. Shen KL, Lin LK, Feng JJ, et al. Expert consensus on clinical prevention and treatment of zinc deficiency in children. Journal of Pediatric Pharmacy. 2020; $26: 46-50$

79. Hotz C. Dietary indicators for assessing the adequacy of population zinc intakes. Food Nutr Bull. 2007; 28: S430-S453.

80. King JC, Hambidge KM, Westcott JL, Kern DL, Marshall G. Daily variation in plasma zinc concentrations in women fed meals at six-hour intervals. J Nutr. 1994; 124: 508-516.

81. Hotz C, Peerson JM, Brown KH. Suggested lower cutoffs of serum zinc concentrations for assessing zinc status: reanalysis of the second National Health and Nutrition Examination Survey data (1976-1980). Am J Clin Nutr. 2003; 78: 756-764.

82. Young GP, Mortimer EK, Gopalsamy GL, et al. Zinc deficiency in children with environmental enteropathy-development of new strategies: report from an expert workshop. Am J Clin Nutr. 2014; 100: 1198-1207.

83. Gibson RS. Zinc: the missing link in combating micronutrient malnutrition in developing countries. Proc Nutr Soc. 2006; 65: 51-60.

84. Ahmed T, Hossain M, Sanin KI. Global burden of maternal and child undernutrition and micronutrient deficiencies. Ann Nutr Metab. 2012; 61 8-17.

85. Hess SY. National Risk of Zinc Deficiency as Estimated by National Surveys. Food Nutr Bull. 2017; 38: 3-17.

86. Engle-Stone R, Ndjebayi AO, Nankap M, Killilea DW, Brown KH. Stunting prevalence, plasma zinc concentrations, and dietary zinc intakes in a 
nationally representative sample suggest a high risk of zinc deficiency among women and young children in Cameroon. J Nutr. 2014; 144: 382-391.

87. Wieringa FT, Dahl M, Chamnan C, Poirot E, Kuong K, Sophonneary P, et al The High Prevalence of Anemia in Cambodian Children and Women Canno Be Satisfactorily Explained by Nutritional Deficiencies or Hemoglobin Disorders. Nutrients. 2016; 8: 348.

88. Mwaniki DL, Omwega AM, Muniu EM, et al. Anaemia and Status of Iron, Vitamin A and Zinc in Kenya. The 1999 National Survey. Nairobi, Kenya: Ministry of Health. 2002

89. Ba Lo N. Statut en zinc des enfants Senegalais et evaluation de l'utilisation de la concentration plasmatique en zinc pour tester l'impact des programmes de fortification. These de Doctorat. No. d'ordre 101. Dakar, Senegal: Université Cheikh Anta Dioph de Dakar. 2014.

90. Dhansay MA, Marais CD, Labadarios D. Zinc Status. The National Food Consumption Survey (NFCS): South Africa, 2005. Pretoria, South Africa: Directorate: Nutrition, Department of Health. 2007.

91. Laillou A, Pham TV, Tran NT, et al. Micronutrient deficits are still public health issues among women and young children in Vietnam. PLoS One 2012; 7: e34906.

92. Martinez-Torres J, Ramirez-Velez R. Zinc deficiency and associated factors in Colombian children; results from the 2010 national nutrition survey; a cross sectional study. Nutr Hosp. 2014; 29: 832-837.

93. Freire $\mathrm{W}$, Ramı 'rez-Luzurlaga $\mathrm{M}$, Belmont $\mathrm{P}$, et al. Tomo I: Encuesta Nacional de Salud y Nutricio 'n de la Poblacio 'n Ecuatoriana de Cero a 59 An os. ENSANUT-ECU 2012. Quito, Ecuador: Ministerio de Salud Pu 'blica/ Instituto National de Estadı 'sticas y Censos. 2014.

94. Guatemala - II Encuesta Nacional de Micronutrientes 2009-2010 (ENMICRON 2009-2010). Ministerio de Salud Publica y Asistencia Social, Instituto National de Estadistica, Universidad del Valle de Guatemala, US Agency for International Development, Centers for Disease Control and Prevention, UNICEF, World Food Programme, Organizacion Panamericana de la Salud, Banco Interamericano de Desarollo, Instituto de Nutricion de Centro America y Panama, Fundacion de la Alimentacion para Centro America y Panama. Guatemala: Ministerio de Salud Publica y Asistencia Social, Instituto National de Estadistica. 2010.

95. Morales-Ruan Mdel C, Villalpando S, GarciaGuerra A, et al. Iron, zinc, copper and magnesium nutritional status in Mexican children aged 1 to 11 years. Salud Publica Mex. 2012; 54: 125-134
96. Maziya-Dixon B, Akinyele IO, Oguntona EB, Nokoe S, Sanusi RA, Harris E. Nigeria Food Consumption and Nutrition Survey 2001 - 2003. Ibadan, Nigeria: International Institute of Tropical Agriculture. 2004.

97. Ministry of Public Health. National Nutrition Survey 2013. Kabul, Afghanistan: Ministry of Public Health. 2015

98. United Nations Children's Fund. Azerbaijan Nutrition Survey (AzNS). Baku, Azerbaijan: United Nations Children's Fund and Government of Azerbaijan Republic. 2013.

99. Ministry of Health and Family, UNICEF Maldives, The Agha Khan University P. Project report. National Micronutrient Survey 2007, Republic of Maldives. Male', Republic of Maldives: Ministry of Health and Family. 2007.

100. Jayatissa R, Gunathilaka M, Herath P, Fernando D. Sri Lanka National Nutrition and Micronutrient Survey. Part II: Iron, Zinc and Calcium Deficiency among Children Aged 6-59 Months. Colombo, Sri Lanka: Ministry of Health Sri Lanka, UNICEF Sri Lanka. 2015.

101. Krebs NF, Hambidge KM. Zinc requirements and zinc intakes of breast-fed infants. Am J Clin Nutr. 1998; 43: 288-292.

102. Cohen RJ, Brown KH, Canahuati J, et al. Effects of age of introduction of complementary foods on infant breastmilk intake, total energy intake, and growth: a randomised intervention study in Honduras. Lancet. 1994; 344: 288-293.

103. Dewey KG, Heinig MJ, Nommsen LA, et al. Zinc status in breastfed infants. Lancet. 1992; 340: 1417.

104. Krebs NF, Reidinger CJ, Robertson AD, et al. Growth and intakes of energy and zinc in infants fed human milk. J Pediatr. 1994; 124: 32-39.

105. Michaelsen KF, Samuelson G, Graham TW, et al. Zinc intake, zinc status and growth in a longitudinal study of healthy Danish infants. Acta Paediatr. 1994; 83: 1115-1121.

106. World Health Organization. Complementary feeding of young children in developing countries: a review of current scientific knowledge. Geneva: World Health Organization. 1998. 